\title{
Alterations in candidate genes PHF2, FANCC, PTCHI and XPA at chromosomal 9q22.3 region: Pathological significance in early- and late-onset breast carcinoma

\author{
Satyabrata Sinha ${ }^{1}$, Ratnesh K Singh1, Neyaz Alam², Anup Roy ${ }^{3}$,
} Susanta Roychoudhury ${ }^{4}$ and Chinmay Kumar Panda*1
}

Address: ${ }^{1}$ Department of Oncogene Regulation, Chittaranjan National Cancer Institute, Kolkata, India, ${ }^{2}$ Department of Surgical Oncology, Chittaranjan National Cancer Institute, Kolkata, India, ${ }^{3}$ Department of Pathology, Medical College, Kolkata, India and ${ }^{4}$ Molecular and Human Genetics Division, Indian Institute of Chemical Biology, Kolkata, India

Email: Satyabrata Sinha - satyabratasinha@gmail.com; Ratnesh K Singh - ratnein@gmail.com; Neyaz Alam - humpty78in@yahoo.co.in; Anup Roy - anuproy@vsnl.net; Susanta Roychoudhury - susanta@iicb.res.in; Chinmay Kumar Panda* - ckpanda.cnci@gmail.com

* Corresponding author

Published: 6 November 2008

Molecular Cancer 2008, 7:84 doi:10.1186/1476-4598-7-84
Received: 22 August 2008

Accepted: 6 November 2008

This article is available from: http://www.molecular-cancer.com/content/7/I/84

(c) 2008 Sinha et al; licensee BioMed Central Ltd.

This is an Open Access article distributed under the terms of the Creative Commons Attribution License (http://creativecommons.org/licenses/by/2.0), which permits unrestricted use, distribution, and reproduction in any medium, provided the original work is properly cited.

\begin{abstract}
Introduction: Younger women with breast carcinoma (BC) exhibits more aggressive pathologic features compared to older women; young age could be an independent predictor of adverse prognosis. To find any existing differences in the molecular pathogenesis of BC in both younger and older women, alterations at chromosomal (chr.) 9q22.32-22.33 region were studied owing to its association in wide variety of tumors. Present work focuses on comparative analysis of alterations of four candidate genes; PHF2, FANCC, PTCHI and XPA located within $4.4 \mathrm{Mb}$ region of the afore-said locus in two age groups of $\mathrm{BC}$, as well as the interrelation and prognostic significance of alterations of these genes.

Methods: Deletion analysis of PHF2, FANCC, PTCHI and XPA were examined in a subset of 47 early-onset (group-A: $\leq 40$ years) and 59 late-onset (group-B: $>40$ years) breast carcinomas using both microsatellite and exonic markers. Methylation Sensitive Restriction analysis (MSRA) was done to check for promoter methylation. Quantitative real-time polymerase chain reaction (Q-PCR) and immunohistochemisty (IHC) was done in some genes to see their relative mRNA and protein expressions respectively. Clinico-pathological correlation of different parameters as well as patient survival was calculated using different statistical softwares like Epilnfo $6.04 \mathrm{~b}$, SPSS 10.0 etc.

Results: Either age group exhibited high frequency of overall alterations in PHF2, FANCC and PTCHI compared to XPA. Samples with alteration (deletion/methylation) in these genes showed reduced level of mRNA expression as seen by Q-PCR. Immunohistochemical analysis of FANCC and PTCHI also supported this observation. Poor patient survival was noted in both age groups having alterations in FANCC. Similar result was also seen with PTCHI and XPA alterations in group-A and PHF2 alterations in group-B. This reflected their roles as prognostic tools in the respective groups in which they were altered.

Conclusion: Overall alterations of PHF2, FANCC and PTCHI were comparatively higher than XPA. Differential association of alterations in FANCC and PTCHI with that of PHF2, XPA and two breast cancer susceptibility genes (BRCAI/BRCA2) in the two age groups suggests differences in their molecular pathogenesis and dysregulation of multiple DNA repair pathways as well as hedgehog dependent stem cell renewal pathway.
\end{abstract}




\section{Introduction}

Breast carcinoma (BC) is the second leading cause of cancer deaths and the most common cancer among women. About $23 \%$ of urban women in eastern India are affected by this disease [1]. Depending on age at onset, BC can be early-onset ( $\leq 40$ years) and late-onset ( $>40$ years) type. However, the cut-off value for early-onset BC varies among investigators, ranging from 35-50 years. Significant differences in clinico-pathological features like large tumor size of higher grade, presence of positive lymph nodes, absence of steroid receptors, and high S-phase fraction in younger women with $\mathrm{BC}$ indicated altered biology and pathogenesis between these two groups of BC [2-4]. Another report showed that in Asian population, BC patients below 40 years have tumors with a poorer prognostic profile. However, this did not translate into a poorer overall survival, and this might be attributable to more aggressive adjuvant treatment of younger patients [5]. All these reports suggested early-onset BC to be a biologically separate disease and independently predict more adverse outcomes. Thus, the molecular analysis of $\mathrm{BC}$ in the two age groups is pertinent to understand the differences in pathogenesis, if any. Our earlier studies on chromosomes (chrs.) $1 \mathrm{p} / \mathrm{q}, 9 \mathrm{p}$ and $11 \mathrm{p} / \mathrm{q}$ showed differential pattern of molecular alterations between the two age groups of BC [3-6]. In order to understand the pathogenesis in detail our aim is to analyze the alterations in other chromosomal regions which showed frequent alterations in BC.

Cytogenetic analyses have revealed a variety of chromosomal aberrations at chr.9q22 in different malignancies including BC [7]. Comparative genomic hybridization (CGH) and flow-cytometric analyses also showed losses at chr.9q in BC [8-10]. Studies in basal cell carcinoma (BCC), squamous cell carcinoma (SCC) as well as bladder, prostate, esophageal and blood cancer detected frequent loss of heterozygosity (LOH) at chr.9q22.3 [11,12]. Significant correlation between losses of chr.9q22.3 with lymph node metastasis in BC is reported [13].

Chr.9q22.3 is a relatively broad region $(8.71 \mathrm{Mb})$ harboring several putative tumor suppressor genes (TSGs). We focused primarily on a $4.4 \mathrm{Mb}$ region between the chr.9q22.32-22.33 where DNA-damage repair genes like FANCC (Fanconi anaemia Complementation-group C), XPA (Xeroderma Pigmentosum A) as well as the hedgehog $(\mathrm{HH})$ pathway associated gene PTCH1 (human homologue of Drosophila patched gene) are localized [13-16]. FANCC localized at chr.9q22.32 (96.89 Mb from p-ter) is associated with reconstitutive and self-renewal potential of haematopoietic stem cells $[17,18]$. Its ablation leads to increased sensitivity to DNA crosslinking agents, loss of FANCD2 activation, and impaired homologous recombination due to poor functioning of the BRCA1-BRCA2-
NBS1-RAD51 mediated DNA repair [19]. Deletion of FANCC in bladder carcinoma, mutations in young-onset pancreatic cancer and Fanconi Anaemia-C patients, and down-regulation in head and neck squamous cell carcinoma (HNSCC) are reported [16,20-22]. PTCH1 (350 Kb downstream to FANCC) is a key regulator in stem cell renewal hedgehog signaling pathway and functions as a tumor suppressor by inhibiting $\mathrm{G}_{1}-\mathrm{S}$ and $\mathrm{G}_{2}-\mathrm{M}$ phases of cell cycle. PTCH1 has been implicated in the development of medulloblastomas, glioblastomas, rhabdomyosarcomas, pancreatic cancers, and other soft tissue tumors [23]. A recent report suggested loss of PTCH1 in 19\% of human breast cancers, and 33\% of breast cancer cell lines [9]. Mutations in PTCH1 gene have been reported in nevoid basal cell carcinoma syndrome (NBCCS), familial BC and its loss induced tumor progression in basal cell carcinoma (BCC) $[24,25]$. Furthermore, immunohistochemical analysis showed reduced expression of PTCH1 due to promoter methylation in BC [26]. XPA (2.23 Mb downstream of PTCH1) gene is essential for assembly of the pre-incision complex during the processing of DNA damage via the nucleotide excision repair (NER) pathway [2729]. Defects in NER are associated with several human autosomal recessive hereditary disorders, such as xeroderma pigmentosum and a marked predisposition to skin cancer (early BCC, SCC and melanoma); early internal tumors [30]. LOH in sporadic ovarian, colon, lung carcinomas and significant association between oral premalignant lesions and polymorphism of XPA are reported $[31,32]$. PHF2, a novel transcriptional regulatory gene associated with hereditary sensory neuropathy type 1 (HSN1) has also been identified at chr.9q22.32, 1.52 Mb upstream of FANCC [33]. However, its role in tumorigenesis is not yet well understood.

Thus, it is evident that alterations of these genes together could cumulatively increase genetic instability and cellular proliferation. Furthermore, study of co-alterations of these genes could be useful in diagnosis and prognosis of a disease. Thus an attempt was made in this study to analyze the alterations (deletion, methylation and expression) of PHF2, FANCC, PTCH1 and XPA in early- and lateonset $\mathrm{BC}$ of Indian patients and correlate them with clinico-pathological differences.

\section{Methods}

\section{Patients, Tumor tissues and cell lines}

One hundred six invasive breast carcinomas (BC) and their corresponding normal tissues or peripheral blood leukocytes (PBL) were randomly collected from 104 unrelated patients, undergoing surgery at the hospital of Chittaranjan National Cancer Institute, Kolkata, India and stored at $-80^{\circ} \mathrm{C}$ over a period of 9 years $(1999-2007)$. The $\mathrm{BC}$ samples were segregated into early-onset BC (group-A: $\leq 40$ years) and late-onset $\mathrm{BC}$ (group-B: $>40$ years) 
depending on the age of the patient at onset of tumor. Informed consent from patients and Research Ethics Committee of the institute were obtained. All these tumors were graded and staged according to UICC TNM classification [34]. Detailed clinico-pathological histories of the patients are presented in Table 1. Part of the freshly operated tissues was directly collected in TRIzol reagent (Invitrogen, USA) for RNA isolation and the rest for DNA extraction. The BC cell line MCF-7 was obtained from American Type Culture Collection and grown according to ATCC instructions.

\section{Microdissection and DNA Extraction}

Contaminant normal cells in the samples were removed by manual microdissection from cryosections $(5 \mu \mathrm{m})$ using surgical knives under a dissecting microscope [Leica $M Z$ 16]. The representative sections from different regions of the specimens were stained with hematoxylin-eosin for diagnosis as well as for marking of tumor-rich regions. The microdissected samples containing at least $70-80 \%$ tumor cells were taken for DNA isolation via proteinase-K digestion, followed by phenol/chloroform extraction procedure [35].

\section{Deletion analysis of the candidate TSGs}

Deletion analysis of the candidate genes was done using 6 microsatellite markers in the following order: Centromere- (PHF2: D9S1803, D9S197, D9S196), (FANCC: D9S1958), (PTCH1: D9S1816) and (XPA: D9S1714) Telomere, selected on the basis of their map positions and heterozygosity (Ensembl release 44; Genome Database).
One exonic marker each from PHF2 exon-18 and FANCC exon-2 were designed using Primer3Input 0.4.0 software to see the homozygous/hemizygous deletion (HD/HED) status of these genes [Table 2].

To detect for deletion in informative microsatellite markers, standard polymerase chain reaction (PCR) analysis with $[\gamma$-p32] ATP end labeled forward primer was done in a $20 \mu \mathrm{l}$ reaction volume as described previously $[35,36]$. Multiplex PCR was done to see deletion (HD/HED) in the non-informative markers [35]. The D9S104 marker at chr.9p13 was used as control (CL) due to low frequency of alterations seen in BC (data not shown). The PCR products were run on $2 \%$ agarose gel, stained with ethidium bromide and visualized under UV transluminator.

Using a densitometric scanner (Bio-Rad GS-800, USA) the number of alleles at LOI (locus of interest) was determined from the signal intensities according to the following formula:

$$
\text { Allele Number }=2 \times \frac{\mathrm{LOI}(\mathrm{T}) / \mathrm{CL}(\mathrm{T})}{\mathrm{LOI}(\mathrm{N}) / \mathrm{CL}(\mathrm{N})}
$$

Where $\mathrm{T}=$ tumor DNA; $\mathrm{N}=$ normal DNA; $\mathrm{CL}=$ Control; LOI $=$ Locus of Interest

Allelic values of $\leq 0.5,0.9-1.7, \geq 1.8$ to $<5.0$ and $>5.0$ will be considered as homozygous deletion (HD), hemizygous deletion (HED), retention of homozygosity (RA) and amplification of the alleles respectively [37].

Table I: Clinico-pathological parameters of early- and late-onset BC

\begin{tabular}{|c|c|c|c|c|c|c|}
\hline \multirow[b]{2}{*}{ Clinical features } & \multicolumn{3}{|c|}{ Group A } & \multicolumn{3}{|c|}{ Group B } \\
\hline & Case & Mean age (years) & Age range (years) & Case & Mean age (years) & Age range (years) \\
\hline \multicolumn{7}{|l|}{ Histological Type } \\
\hline Ductal & 45 & 34 & $25-40$ & 59 & 53 & $4 I-77$ \\
\hline Lobular & 2 & 28 & $20-35$ & 0 & - & - \\
\hline \multicolumn{7}{|l|}{ Clinical Stage } \\
\hline TNM Stage I & 1 & 40 & 40 & 2 & 48 & $45-50$ \\
\hline TNM Stage II & 7 & 33 & $23-40$ & 21 & 51 & $42-61$ \\
\hline TNM Stage III & 36 & 35 & $20-40$ & 33 & 53 & $41-77$ \\
\hline TNM Stage IV & 3 & 37 & $36-38$ & 3 & 57 & $48-72$ \\
\hline \multicolumn{7}{|l|}{ Tumor Differentiation } \\
\hline Grade I & 4 & 32 & $20-40$ & 8 & 52 & $43-61$ \\
\hline Grade 2 & 32 & 33 & $18-40$ & 39 & 47 & $41-42$ \\
\hline Grade 3 & II & 38 & $33-40$ & 12 & 56 & $42-77$ \\
\hline \multicolumn{7}{|l|}{ Lymph Node } \\
\hline Positive & 33 & 35 & $26-40$ & 48 & 52 & $42-77$ \\
\hline Negative & 14 & 31 & $18-40$ & 11 & 51 & $4 I-65$ \\
\hline
\end{tabular}


Table 2: Summary of oligonucleotides

\begin{tabular}{|c|c|c|c|c|c|}
\hline Primers & Location & $\begin{array}{l}\text { Analytical } \\
\text { purpose }\end{array}$ & Forward Primer & Reverse Primer & Size (bp) \\
\hline PHF2 Ex-18 & $9 q 22.32$ & HD/HED & 5'-ACTCCTGCCTGCAGACCAC-3' & 5'-ССTGCTCTTCCTCGTAGTCG-3' & 168 \\
\hline FANCC Ex-2 & $9 q 22.32$ & HD/HED & 5'-TGGCTCAAGATTCAGTAGATCTTTC-3' & 5'-TTTCAAGGCTTCATACATCTTCC-3' & 158 \\
\hline PHF2 promoter & -893 to -670 region & Methylation & 5'-GTGGTGTCCCAACCAGAAAC-3' & 5'-GGGACCCCGAGGATAAGATA-3' & 223 \\
\hline FANCC promoter & -319 to -144 region & Methylation & 5'-TTTTACCCCGTTGACAAAGC-3' & 5'-CGGTACTGCTCCAGTGTTCC-3' & 175 \\
\hline PTCHI promoter & -715 to -420 region & Methylation & 5'-CGAGGAGCACAAGAAAGCAG-3' & 5'-AGAAAGAGCCAGCGAATCC-3' & 295 \\
\hline XPA promoter Ex.I & -126 to +56 region & Methylation & 5'-AGGCGCTCTCACTCAGAAAG-3' & 5'-TCCGCGGGTTGCTCTAAA-3' & 182 \\
\hline PTCHI Ex.*23 & Intron $22-23$ to Ex.23 & SSCP & 5'-ТСТААСССАСССТСАСССТС-3' & 5'-ATTGCTAGGGCCAGAATGCC-3' & 226 \\
\hline PTCHI Ex.23 & Ex.23 to Intron $23-24$ & SSCP & 5'-TTCTGCCTCCGTGACTGTC-3' & 5'-СTCTAGGTCCCTTGGCTGC-3' & 265 \\
\hline PHF2 Ex. 18-19 & Coding regions of exons & Q-PCR & 5'-ACTCCTGCCTGCAGACCAC-3' & 5'-TCGACCGGGACTTAAAGATG-3' & 257 \\
\hline FANCC Ex. 7-8 & Coding regions of exons & Q-PCR & 5'-TGGAGGCTCTCCTCATCTGT-3' & 5'-GCATTCGATCCTTCTCAGACA-3' & 223 \\
\hline PTCHI Ex. I-2 & Coding regions of exons & Q-PCR & 5'-GACCGGGACTATCTGCA-3' & 5'-GAGGAGGCCCACAACC-3' & 186 \\
\hline$\beta 2$ Microglobulin & $15 q 21-q 22.2$ & Q-PCR & 5'-GTGCTCGCGCTACTCTCTCT-3' & 5'-TCAATGTCGGATGGATGAAA-3' & 153 \\
\hline$\beta$-3A-adaptin (KI*) & $5 q 14.1$ & $\begin{array}{l}\text { DNA cleavage } \\
\text { control }\end{array}$ & 5'-TGCCCTCTGGACTGGAACCT-3' & 5'-CCTGAGCCCAGCCCAAGTC-3' & 445 \\
\hline $\operatorname{RAR} \beta 2(\mathrm{~K} 2 * *)$ & $3 p 24.2$ & $\begin{array}{l}\text { DNA integrity } \\
\text { control }\end{array}$ & 5'-AGAGTTTGATGGAGTTGGGT-3' & 5'-CATTCGGTTTGGGTCAATCC-3' & 229 \\
\hline
\end{tabular}

\section{PCR based Methylation sensitive restriction analysis (MSRA)}

Promoter methylation of PHF2, FANCC, PTCH1 and XPA were done in all BC samples by MSRA using methyl-sensitive restriction enzyme HpaII and its methylation in-sensitive iso-schizomer MspI [38]. Primer sequences are listed in Table 2. Promoter region of PTCH1 gene harbored 6 CCGG-recognition sites for the above restriction enzymes while, there were two CCGG sites in FANCC promoter and one each in PHF2 and XPA gene promoters. The 445-bp fragment of $\beta$-3A adaptin gene (K1) and 229bp fragment of RAR $\beta 2$ exon-1 (K2) was used as digestion and integrity controls respectively [39].

\section{Mutation analysis}

Mutation analysis of exon-23 of PTCH1 was done in 60 BC samples by single strand conformation polymorphism (SSCP) analysis using [ $\alpha$-p32] dCTP as described previously [36]. Two primers from exon 23 (Ex*23 and Ex-23) were designed to cover the entire exon- 23 which is a mutational hotspot and reported to be mutated in a variety of cancers [Table 2]. Sequencing for both strands of the samples showing abnormal band shift in autoradiographs were done using 3100-Avant Genetic Analyzer (PE Applied Biosystems Inc, USA).

\section{Quantitative Real-time PCR (Q-PCR)}

The mRNA expression of PHF2, FANCC, PTCH1 and XPA in normal breast tissue $(\mathrm{n}=6)$, and primary $\mathrm{BC}(\mathrm{n}=14)$ and 1 cell line (MCF-7) was analyzed by quantitative realtime (Q-PCR). Total RNA was isolated from samples using TRIzol reagent according to the manufacturer's protocol (Ambion Inc.). Complementary-DNA (cDNA) was synthesized from $1 \mu \mathrm{g}$ total RNA using Random hexamer (Invitrogen, USA) and Superscript III (Invitrogen, USA) according to manufacturer's protocol. PCR was performed in 40 cycles on an ABI Prism 7500 using Power SYBR
Green PCR Master Mix (Applied Biosystems, USA) in a final volume of $15 \mu \mathrm{l}$. Each sample was run in triplicates and average value was considered for analysis. Relative quantities $(\Delta \Delta \mathrm{Ct})$ were obtained by normalization against human beta2-microglobulin gene [40]. Primers are listed in Table 2.

\section{Immunohistochemistry}

Immunostaining of FANCC and PTCH1 protein were done in 20 primary breast carcinomas using the AvidinBiotin-Peroxidase Complex (ABC) staining kit according to manufacturers protocol (Santa Cruz Biotechnology, CA, USA). About 3-5 $\mu \mathrm{m}$ paraffin sections were de-paraffinized, rehydrated and reacted overnight with primary antibodies (goat polyclonal IgG, sc-18110 for FANCC (C14) and sc-6149 for PTCH1 (G-19); Santa Cruz, CA, USA) at a dilution of $1: 100$ at $4^{\circ} \mathrm{C}$. Horse-Radish-Peroxidase conjugated rabbit anti-goat secondary antibody (sc-2768) was added at 1:500 dilutions. The slides were developed using 3-3' diaminobenzidine (DAB) as the chromogen and counterstained with hematoxylin. The staining intensity $(-=$ negative,$+=$ weak, $2+=$ moderate, and $3+=$ strong) and the percentage of positive cells $(-=0 \%,+=1-$ $24 \%, 2+=25-49 \%$, and $3+=50-100 \%)$ were evaluated by two observers independently [41].

\section{Statistical Analysis of Clinical Data}

Fisher's exact test was used to determine the association between tumors genetic profile and different clinico-pathological features. Survival analysis was performed according to Kaplan-Meier method. Post-operative overall survival was measured from the date of surgery to the date of last follow-up or death (up to 5 years). Probability value (P-value) $\leq 0.05$ was considered statistically significant. All the statistical analysis was performed using statistical programs EpiInfo 6.04b, SPSS 10.0 (SPSS Inc. Chicago, IL, USA). 


\section{Results}

Deletion analysis of candidate TSGs loci

Deletion mapping identified LOH in microsatellite markers and both hemi/homozygous deletion in the exonic markers [Figure 1]. Compared to XPA, high deletion was seen in the PHF2, FANCC and PTCH1 loci in both age groups of BC [Figure 2; Additional Files 1 and 2]. Order of deletion frequencies were: group-A: FANCC $(47 \%)>$ PHF2 (43\%) > PTCH1 (30\%) > XPA (21\%) and group-B: FANCC $(49 \%)>$ PHF2 $(42 \%)>$ PTCH1 $(27 \%)>$ XPA (20\%). LOH was concordant with hemizygous deletion in exonic markers. Homozygous deletions were restricted to

(a)
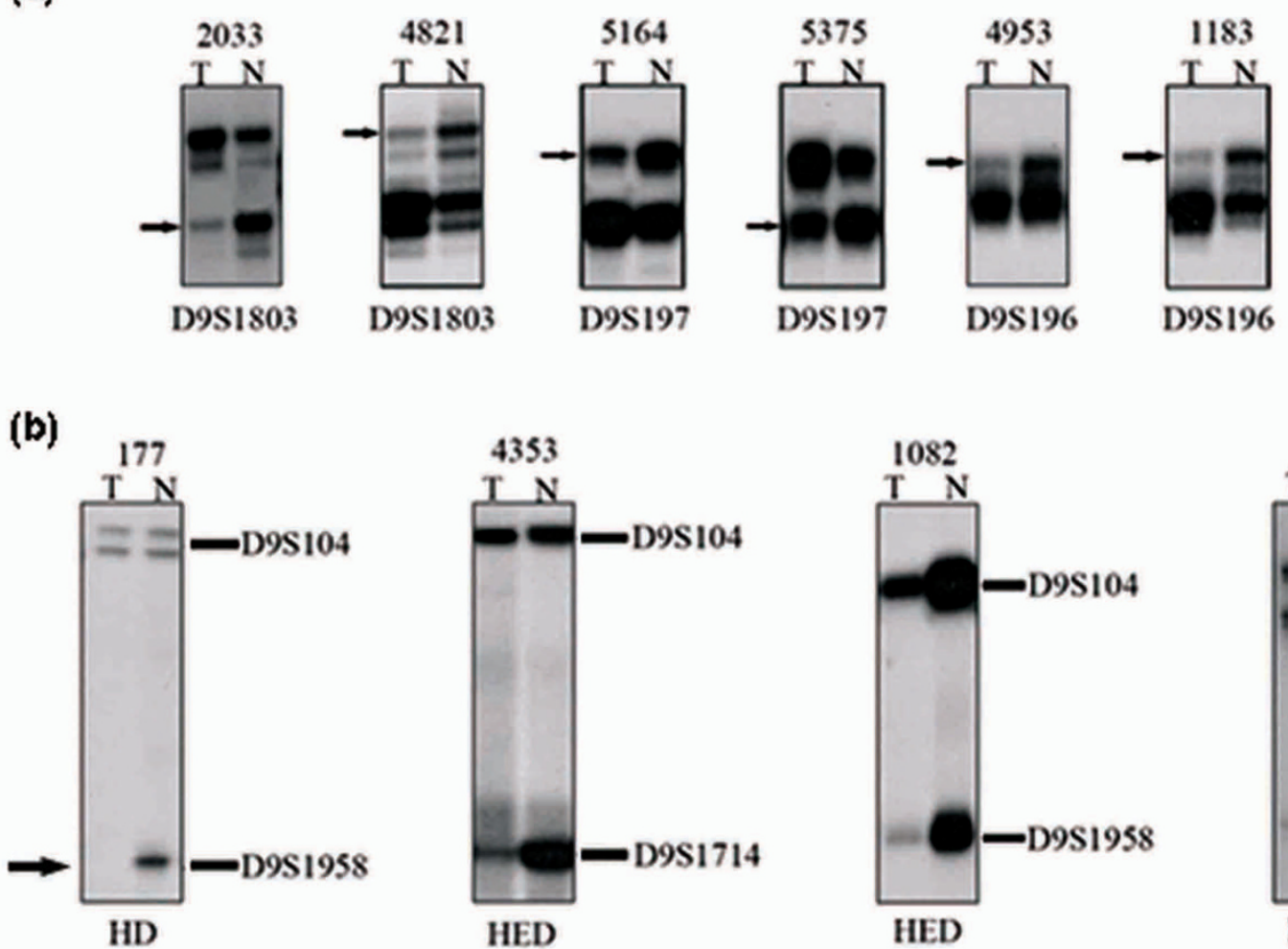

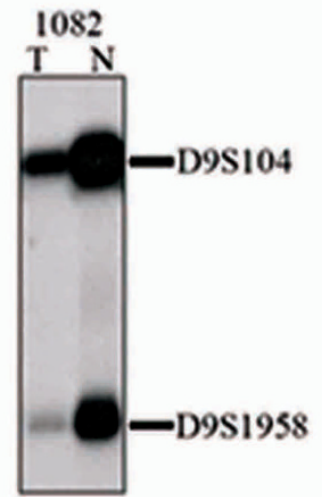

HED

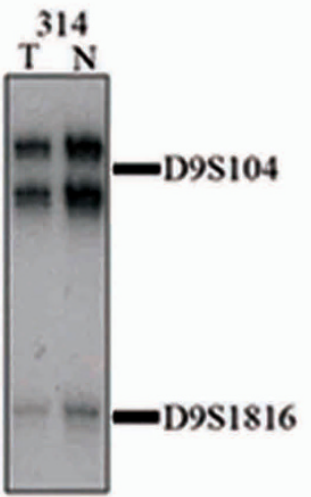

HED

(c)
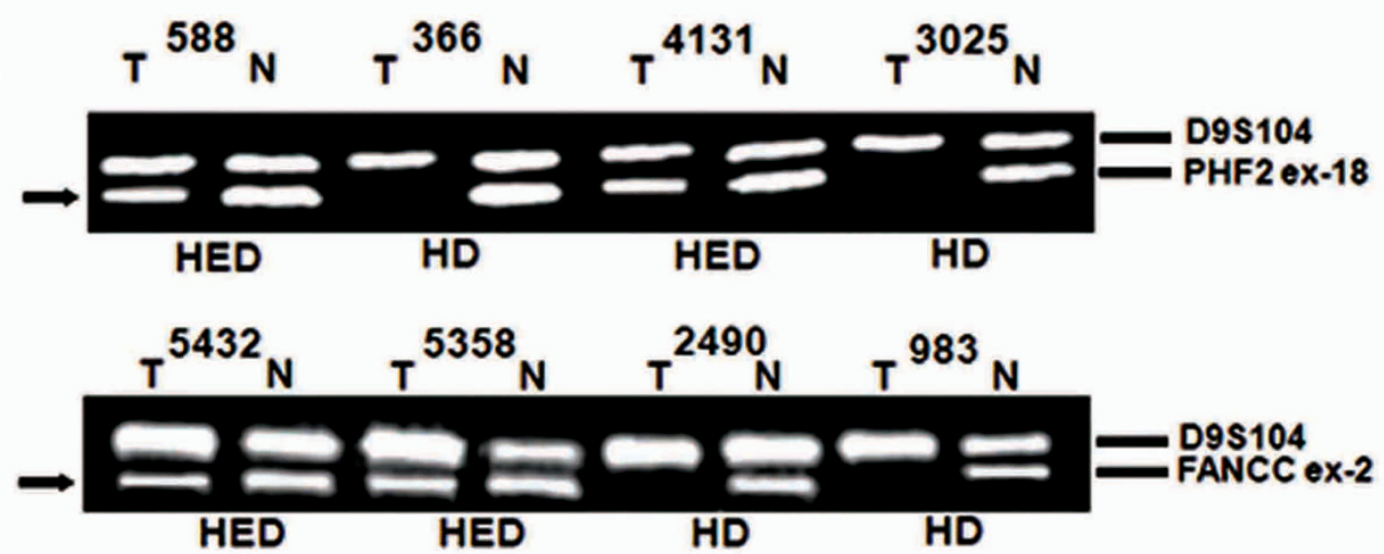

Figure I

(a) Representative autoradiograph showing loss of heterozygosity (LOH) (b) homozygous/hemizygous deletion (HD/HED) analysis in microsatellite markers (c) HD/HED of exonic markers. $\rightarrow$ indicates loss of corresponding alleles. 

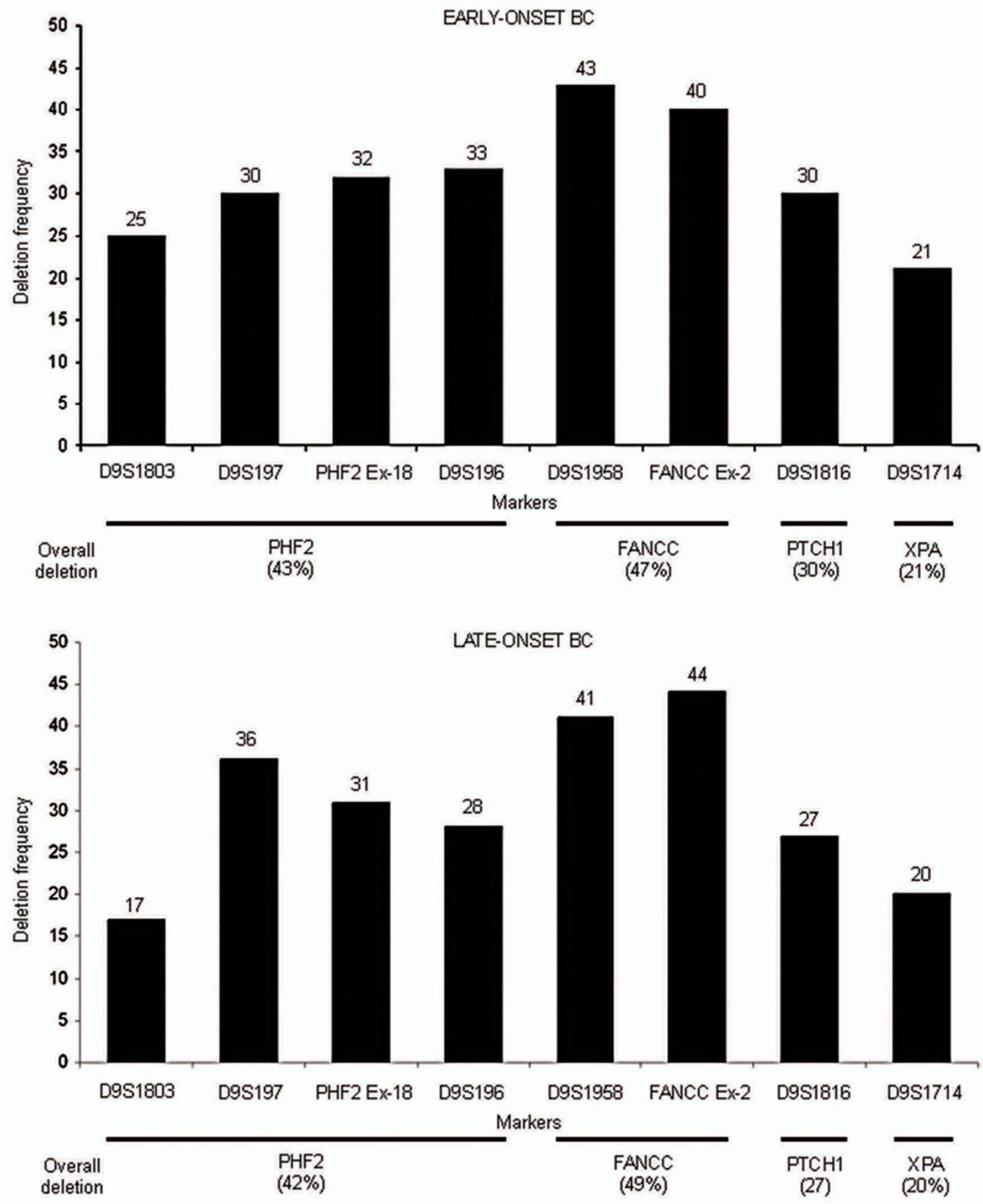

Figure 2

Pattern of deletion at different chr.9q22.32-22.33 markers in early- and late-onset BC. 
PHF2 exon-18 and FANCC exon-2. Interstitial deletion or loss of entire region was observed in 32\% (15/47) group$A$ and $42 \%(25 / 59)$ group-B samples indicating the importance of this region in $\mathrm{BC}$.

Deletion between PTCH1 and XPA was significantly associated in both group- $\mathrm{A}(\mathrm{P}=0.02)$ and group- $\mathrm{B}(\mathrm{P}=$ 0.00003) [Table 3].

\section{Promoter Methylation analysis}

Comparable frequencies of promoter methylation were observed in both age groups. In group-A, PTCH1 exhibited highest 32\% methylation followed by FANCC (30\%), PHF2 (21\%) and XPA (17\%). Contrastingly, in group-B, FANCC showed highest 39\% methylation followed by $36 \%$ in PTCH1, 24\% in XPA and 22\% in PHF2 [Figure 3; Additional File 3]. Concomitant methylation in all the candidate genes was observed in two early-onset and five late-onset BC samples.

Significant association was observed between methylation of FANCC and PHF2 in both group-A $(P=0.02)$ and group- $B(P=0.001)$. Methylation of XPA was significantly associated with methylation of PHF2 $(P=0.03)$ and FANCC $(\mathrm{P}=0.0001)$ in group-A and that of PTCH1 $(\mathrm{P}=$ 0.01 ) in group-B [Table 4]. In FANCC, both deletion and methylation showed significant association in both groups $(\mathrm{P}=0.004$ and 0.002$)$ while, in PTCH1 significant association was observed only in group-A $(P=0.002)$ [data no shown].

\section{Mutation analysis of PTCHI Exon-23}

SSCP analysis in 60 primary BC samples revealed no abnormal band shifts in PTCH1 exon-23. Direct sequencing of 20 out of these 60 samples showed no changes in the nucleotide sequences.

\section{Association between overall alterations of candidate TSGs} Either deletion or methylation of any one of the 4 candidate genes were seen in about $91 \%$ of the samples in both groups indicating the importance of chr.9q22.32-22.33 in the development of BC. Overall alterations (deletion/ methylation) of PHF2, FANCC, PTCH1 and XPA were comparable in both age groups, them showing 60\%, 53\%, $43 \%$ and $36 \%$ alterations respectively in group-A and $59 \%, 59 \%, 58 \%$ and $36 \%$ in group-B (Figure 4; Additional File 4). Overall alterations of PTCH1 showed significant association with XPA in both group-A $(\mathrm{P}=0.003)$ and group- $\mathrm{B}(\mathrm{P}=0.007)$. However, overall alterations of PHF2 showed significant association with either FANCC $(\mathrm{P}=0.005)$ or XPA $(\mathrm{P}=0.05)$ only in group-B [data not shown].

\section{Expression analysis of the candidate genes}

Q-PCR analysis of PHF2, FANCC and PTCH1 mRNA revealed reduced mRNA expression of in all these genes. In respect to non-tumor control, relative fold reduction in

Table 3: Association between deletions of the 4 candidate genes in early- and late-onset BC

\begin{tabular}{|c|c|c|c|c|c|c|c|c|c|c|c|c|c|c|c|c|c|}
\hline & & \multicolumn{8}{|c|}{ Group-A } & \multicolumn{8}{|c|}{ Group-B } \\
\hline & & \multicolumn{2}{|c|}{ PHF2 } & \multicolumn{2}{|c|}{ FANCC } & \multicolumn{2}{|c|}{ PTCHI } & \multicolumn{2}{|c|}{ XPA } & \multicolumn{2}{|c|}{ PHF2 } & \multicolumn{2}{|c|}{ FANCC } & \multicolumn{2}{|c|}{ PTCHI } & \multicolumn{2}{|c|}{ XPA } \\
\hline & & D+ & D- & D+ & D- & D+ & D- & D+ & D- & D+ & D- & D+ & D- & D+ & D- & D+ & D- \\
\hline \multirow[t]{2}{*}{ PHF2 } & D+ & - & - & 9 & 11 & 6 & 14 & 6 & 14 & - & - & 13 & 12 & 5 & 20 & 6 & 19 \\
\hline & D- & & & 13 & 14 & 8 & 19 & 4 & 23 & & & 16 & 18 & 11 & 23 & 6 & 28 \\
\hline \multicolumn{2}{|c|}{ P value } & \multicolumn{2}{|c|}{-} & \multicolumn{2}{|c|}{0.83} & \multicolumn{2}{|c|}{0.98} & \multicolumn{2}{|c|}{0.21} & \multicolumn{2}{|c|}{-} & \multicolumn{2}{|c|}{0.71} & \multicolumn{2}{|c|}{0.29} & \multicolumn{2}{|c|}{0.55} \\
\hline \multirow[t]{2}{*}{ FANCC } & D+ & - & - & - & - & 5 & 17 & 5 & 17 & - & - & - & - & 7 & 22 & 5 & 24 \\
\hline & D- & & & & & 9 & 16 & 5 & 20 & & & & & 9 & 21 & 7 & 23 \\
\hline \multicolumn{2}{|c|}{$p$ value } & \multicolumn{2}{|c|}{-} & \multicolumn{2}{|c|}{-} & \multicolumn{2}{|c|}{0.32} & \multicolumn{2}{|c|}{0.82} & \multicolumn{2}{|c|}{-} & \multicolumn{2}{|c|}{-} & \multicolumn{2}{|c|}{0.61} & \multicolumn{2}{|c|}{0.56} \\
\hline \multirow[t]{2}{*}{ PTCHI } & D+ & - & - & - & - & - & - & 6 & 8 & - & - & - & - & - & - & 9 & 7 \\
\hline & D- & & & & & & & 4 & 29 & & & & & & & 3 & 40 \\
\hline \multicolumn{2}{|c|}{ p value } & \multicolumn{2}{|c|}{-} & \multicolumn{2}{|c|}{-} & & & & & & & & & & & 0.0 & 3* \\
\hline
\end{tabular}

Abbreviations used are: D+: Deletion positive; D-: Deletion negative; * indicates $p$ value significance 


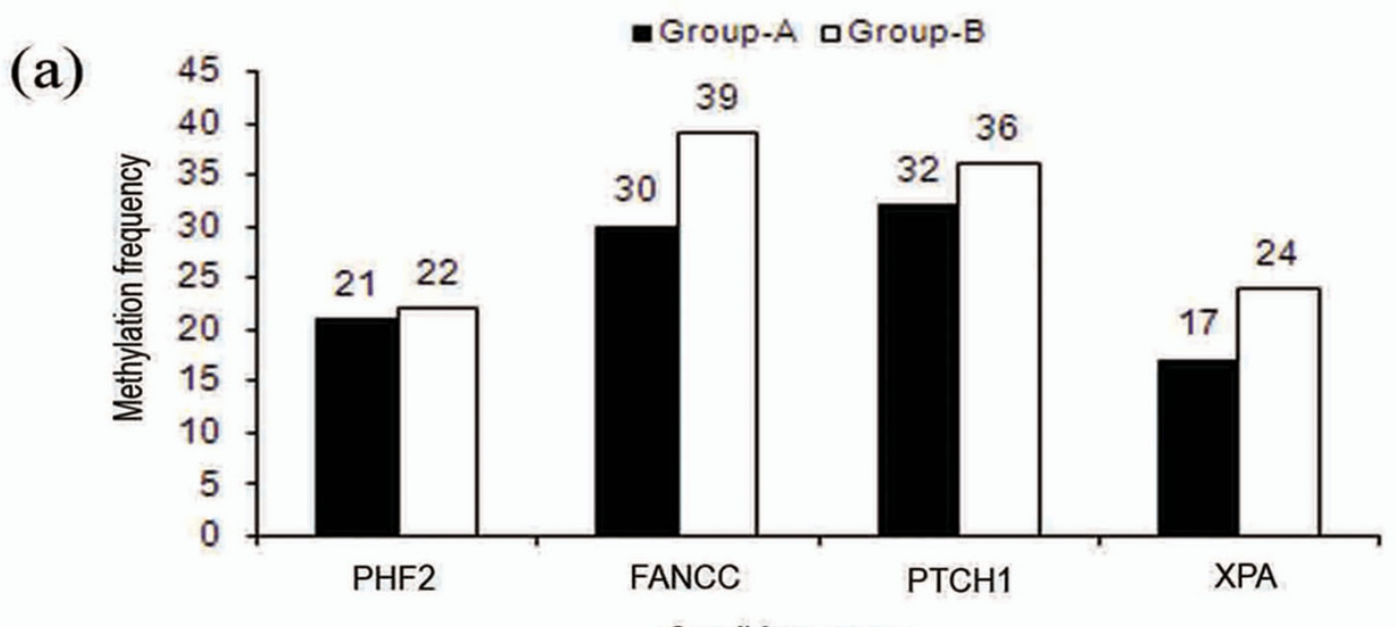

Candidate genes
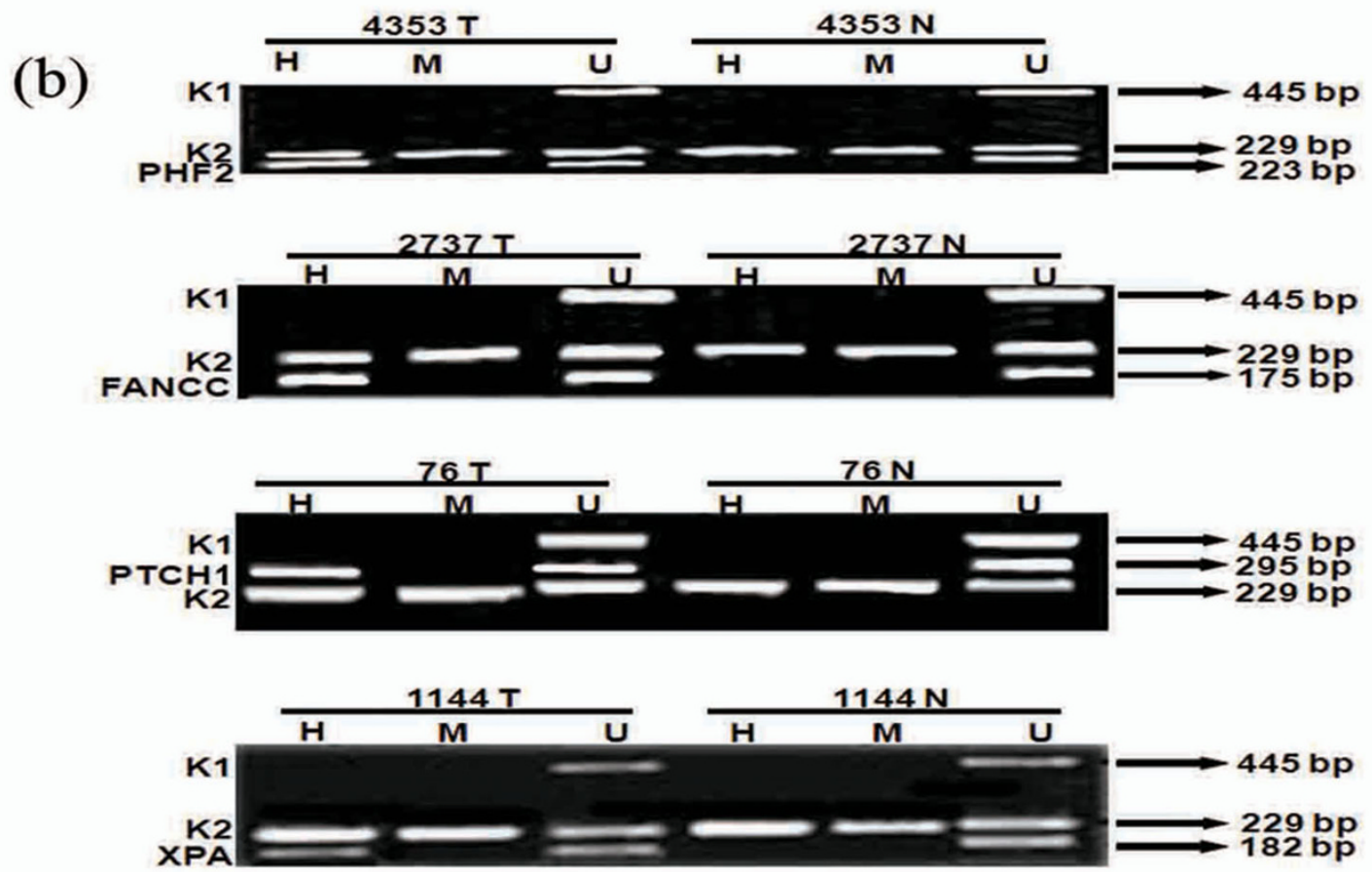

Figure 3

(a) Histogram showing pattern of methylation in the four genes. (b) Representative agarose gels showing methylation in PHF2, FANCC, PTCHI and XPA done by MSRA. H, Hpall digested DNA; M, Mspl digested DNA; U, undigested DNA. Controls: A 445-bp fragment of $\beta 3 A$ adaptin gene (KI) and 229-bp fragment of RARß2 exon-I (K2). 
Table 4: Association between methylation of the 4 candidate genes in early- and late-onset BC

\begin{tabular}{|c|c|c|c|c|c|c|c|c|c|c|c|c|c|c|c|c|c|}
\hline & & \multicolumn{8}{|c|}{ Group-A } & \multicolumn{8}{|c|}{ Group-B } \\
\hline & & \multicolumn{2}{|c|}{ PHF2 } & \multicolumn{2}{|c|}{ FANCC } & \multicolumn{2}{|c|}{ PTCHI } & \multicolumn{2}{|c|}{ XPA } & \multicolumn{2}{|c|}{ PHF2 } & \multicolumn{2}{|c|}{ FANCC } & \multicolumn{2}{|c|}{ PTCHI } & \multicolumn{2}{|c|}{ XPA } \\
\hline & & $M+$ & M- & $M+$ & M- & M+ & M- & M+ & M- & M+ & M- & $M+$ & M- & M+ & M- & M+ & $M$ \\
\hline \multirow[t]{2}{*}{ PHF2 } & M+ & - & - & 6 & 4 & 2 & 8 & 4 & 6 & - & - & 10 & 3 & 7 & 6 & 5 & 8 \\
\hline & M- & & & 8 & 29 & 13 & 24 & 4 & 33 & & & 13 & 33 & 14 & 32 & 9 & 37 \\
\hline \multicolumn{2}{|c|}{ p value } & \multicolumn{2}{|c|}{-} & \multicolumn{2}{|c|}{$0.02 *$} & \multicolumn{2}{|c|}{0.36} & \multicolumn{2}{|c|}{$0.03 *$} & \multicolumn{2}{|c|}{-} & \multicolumn{2}{|c|}{$0.001 *$} & \multicolumn{2}{|c|}{0.12} & \multicolumn{2}{|c|}{0.16} \\
\hline \multirow[t]{2}{*}{ FANCC } & M+ & - & - & - & - & 6 & 8 & 7 & 7 & - & - & - & - & 7 & 16 & 7 & 16 \\
\hline & $M-$ & & & & & 9 & 24 & 1 & 32 & & & & & 14 & 22 & 7 & 29 \\
\hline \multicolumn{2}{|c|}{ p value } & \multicolumn{2}{|c|}{-} & \multicolumn{2}{|c|}{-} & \multicolumn{2}{|c|}{0.29} & \multicolumn{2}{|c|}{$0.0001 *$} & \multicolumn{2}{|c|}{-} & \multicolumn{2}{|c|}{-} & \multicolumn{2}{|c|}{0.51} & \multicolumn{2}{|c|}{0.33} \\
\hline \multirow[t]{2}{*}{ PTCHI } & M+ & - & - & - & - & - & - & 4 & II & - & - & - & - & - & - & 9 & 12 \\
\hline & $M-$ & & & & & & & 4 & 28 & & & & & & & 5 & 33 \\
\hline \multicolumn{2}{|c|}{ p value } & \multicolumn{2}{|c|}{-} & \multicolumn{2}{|c|}{-} & & & & & & & & & & & & \\
\hline
\end{tabular}

Abbreviations used are: M+: Methylation positive; M-: Methylation negative; * indicates p value significance

expression of these genes in primary tumors was seen in the following order: FANCC $(31.6 \pm 36.7)>$ PHF2 $(26.54$ $\pm 44.41)>$ PTCH1 $(19.3 \pm 27.8)$. Reduced expression was noted in nearly $33-40 \%$ of the tumors, greater than the mean fold in reduction of the respective genes [Figure 5; Additional File 5]. Immunohistochemical analysis showed both FANCC [Figure 6a-c] and PTCH1 proteins [Figure 6d-f] to be localized exclusively within the cytoplasm. Strong cytoplasmic staining in genes observed in samples with no alterations (deletion and/or methyla-

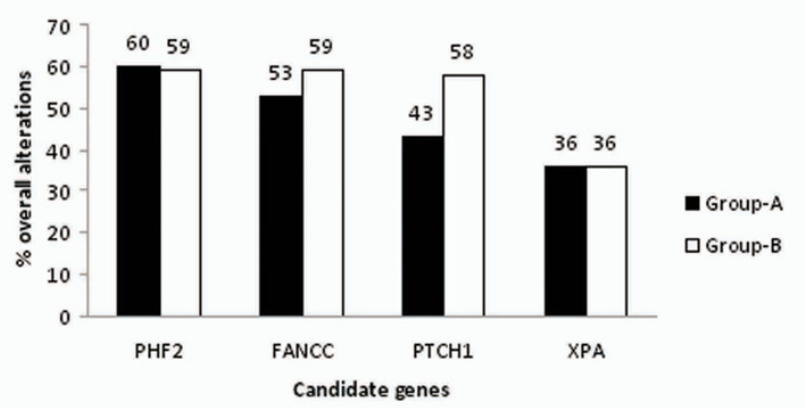

Figure 4

Patten of overall alterations in $\mathbf{4}$ candidate genes at chr9q22.32-22.33. tion) of the candidate genes, while moderate to negative expression was observed in samples harboring genetic and/or epigenetic alterations. Table 5 indicates significant association between alterations of FANCC $(\mathrm{P}=0.004)$

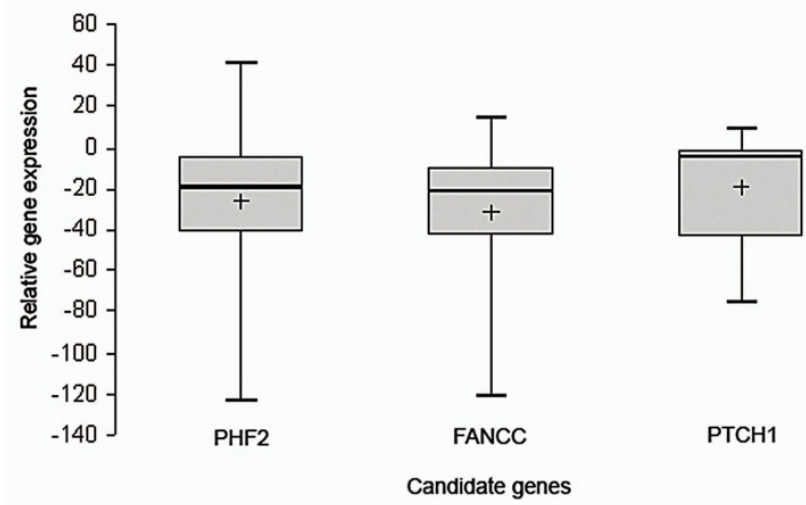

Figure 5

Box plot representing the relative expression level of PHF2, FANCC and PTCHI genes done by Q-PCR as shown in the $y$-axis. Each box shows the distribution of expression levels from 25 th to 75 th percentile. The median is shown as a line across the box, whereas the ' + ' is the calculated mean expression level for the particular subtype. Overall, the cases consistently had lower expression of the candidate TSGs. 

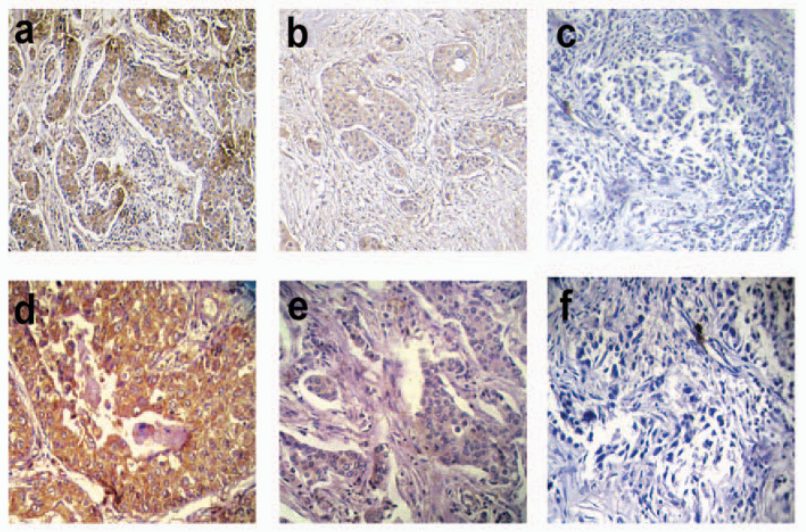

Figure 6

Immunohistochemistry of FANCC and PTCHI (a-c) FANCC expression pattern (d-f) PTCHI expression pattern. BC samples showing high (a and d) or moderate (b and $e$ ) or low (c and $f$ ) expression of FANCC and PTCHI genes respectively. Arrow $(\rightarrow)$ indicates the expression pattern of FANCC and PTCHI in primary BC. All magnifications are at $20 \times$.

and PTCH1 $(\mathrm{P}=0.001)$ genes with their protein expression as seen by immunohistochemistry. The immunohistochemical analysis of PHF2 was not done due to the lack of commercially available antibody.

\section{Association with some DNA repair genes}

Of the 106 BC samples a subset of 29 group-A and 33 group-B breast samples were further studied to find out the association between the candidate genes with some breast cancer susceptibility genes like BRCA1, BRCA2 that are intermittently associated with breast cancer. Deletion status of BRCA1 and BRCA2 in the 29 group-A and 33 group-B samples has already been reported [42]. Overall alterations of FANCC showed significant association with deletion of BRCA2 in both group-A $(\mathrm{P}=0.03)$ and group$B(P=0.02)$. However, only in group-A, significant association was observed between overall alterations of PTCH1 and deletion of BRCA1 $(P=0.04)$ [Additional File $6]$.

\section{Clinico-pathological association and patient survival}

In group-A, both deletion and methylation of PTCH1 were significantly associated with advanced stages. Moreover, its deletion in group-A and methylation in group-B were significantly associated with higher tumor grades $(\mathrm{P}$ $=0.02)$ and lymph node metastasis $(P=0.03)$ respectively. Methylation of XPA also showed significant association with lymph node invasion $(\mathrm{P}=0.04)$ in group-A [Additional Files 7 and 8].

The clinical outcome in the two age groups was investigated for a period of 5 years. The patient follow-up ranged from 2-60 months in both age groups. The mean and median follow-up period in group-A was 32 months each

Table 5: Immunohistochemical expression of FANCC and PTCHI with respect to their alterations

\begin{tabular}{|c|c|c|c|c|}
\hline & FANCC alteration & & PTCHI alteration & \\
\hline Sample No. & Deletion/Methylation & FANCC protein expression & Deletion/Methylation & PTCHI protein expression \\
\hline 1186 & $+/-$ & - & $-/-$ & +++ \\
\hline 374 & $-/+$ & - & $-/+$ & - \\
\hline 4187 & $+/-$ & + & $-/+$ & - \\
\hline 3266 & $+/+$ & - & $-/-$ & +++ \\
\hline 5451 & $-/-$ & +++ & $-/-$ & +++ \\
\hline 5596 & $-/-$ & +++ & $-/+$ & - \\
\hline 3156 & $+/+$ & - & $-/-$ & +++ \\
\hline 4604 & $+/+$ & - & $+/+$ & - \\
\hline $4|3|$ & $-/+$ & ++ & $+/-$ & - \\
\hline 2490 & $+/-$ & - & $-/+$ & - \\
\hline 2400 & $+/+$ & - & $-/+$ & ++ \\
\hline 796 & $+/-$ & ++ & $-/+$ & - \\
\hline 880 & $-/-$ & +++ & $+/+$ & - \\
\hline 314 & $+/-$ & ++ & $+/-$ & ++ \\
\hline 5337 & $+/-$ & - & $-/-$ & +++ \\
\hline 1865 & $+/+$ & - & $-/+$ & - \\
\hline 4671 & $-/-$ & +++ & $+/-$ & + \\
\hline 3025 & $+/+$ & - & $-/+$ & - \\
\hline 6155 & $-/+$ & - & $-/-$ & +++ \\
\hline 1144 & $-/-$ & +++ & $-/+$ & - \\
\hline$P$ value & \multicolumn{2}{|c|}{$P=0.004 *$} & \multicolumn{2}{|c|}{$P=0.001 *$} \\
\hline
\end{tabular}

Abbreviations used are: Sample no is patient's registration number 
while, in group-B it was 35 months and 39 months respectively. Log-rank test uncovered statistically significant differences in overall patient survival between cases with presence and absence of any alteration (deletion and/or methylation $)$ in FANCC $(\mathrm{P}=0.005)$, PTCH1 $(\mathrm{P}=0.03)$ and XPA $(\mathrm{P}=<0.00001)$ among group-A samples. However in group-B samples, alterations of only FANCC $(\mathrm{P}=$ 0.01 ) was significantly associated with survival [Figure 7].

\section{Discussion}

Previous studies have shown differences in alteration pattern of various chromosomal regions in the development of early- and late-onset BC [3-6]. To delineate the molecular pathogenesis of $\mathrm{BC}$ in the two age groups in detail, molecular alterations (deletion/methylation) of candidate genes PHF2, FANCC, PTCH1 and XPA within chr.9q22.32-22.33 region were analyzed due to its association with a wide variety of tumors including BC. Nearly $91 \%$ samples in both groups presented alterations in any one of the genes. Compared to XPA, overall frequencies of alterations in PHF2, FANCC and PTCH1 were higher (Figure 4). This is the first report of its kind. The overall alterations of these genes were differentially associated in the two age groups and indicated differences in pathogenesis and adverse prognosis in patients.

Significant association between deletion and methylation of FANCC in both groups and PTCH1 in group-A only, suggested them to be candidate TSGs in BC. The concord-

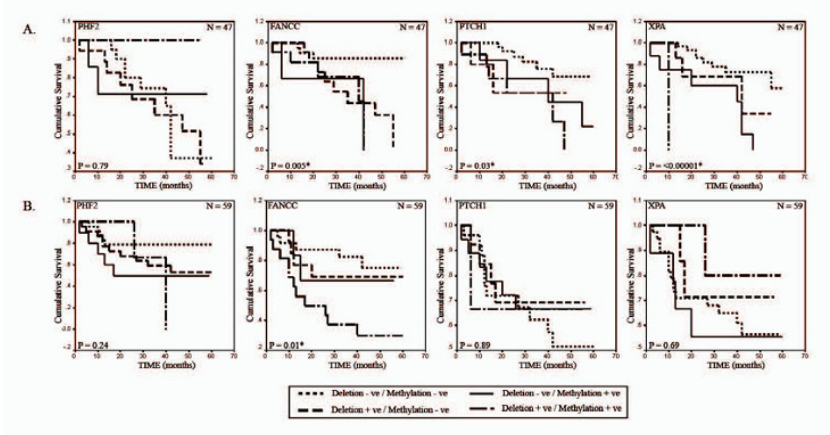

Figure 7

Kaplan-Meier 5-year survival probability curves with cumulative survival of $B C$ patients by alteration status of PHF2, FANCC, PTCHI and XPA in (A.) earlyonset and (B.) late-onset BC. Survival time was defined as the time from surgery to the patient's death, known recurrence or the last time the patient was known to be alive. The log rank test was used to assess the differences in the patient survival between cases with plot for the differences in overall survival among cases with any alteration (Deletion +ve/Alteration -ve or Deletion -ve/Methylation +ve or Deletion +ve/ Methylation +ve) and no alteration (Deletion -ve/Methylation -ve) of the analyzed genes. $N$ denotes sample size. ance between deletion/methylation of these genes with protein expression also supported this fact. Down-regulation in mRNA expression of these genes were also seen in MCF-7 and primary BC samples. Deletion, mutation and down-regulation of FANCC have also been reported in other malignancies [16-22]. Significant association of FANCC-XPA methylation in group-A and FANCC-BRCA2 deletion in both age groups supported interlink between multiple DNA repair pathways. This warrants further analysis of other members of this repair pathway needs to be done. The association noted between FANCC alterations and adverse patient survival in either age group suggests it as a prognostic marker.

Contrary to previous reports, frequencies of alterations in PTCH1 in our samples were higher [9]. This may be due to differences in etiology, ethnicity and techniques used in our study. Mutations in exon-23 of PTCH1 were reported in BCC but, no such changes were seen in our samples [43]. Significant association between PTCH1 and XPA deletion in both groups as well as between their methylation in group-B suggested some functional relationship between hedgehog dependent stem cell renewal pathway and the NER pathway. Coincident germline mutations in PTCH1 and BRCA1 genes have been seen in familial BC and NBCCS [24]. Similarly, correlation between PTCH1 alterations with BRCA1 deletion in group-A suggested its association with other DNA repair pathways. Poor survival in group-A patients with PTCH1 alterations indicated its prognostic significance. In PHF2 and XPA no association was seen between their deletion and methylation. So, other mechanisms of inactivation such as mutation cannot be ruled out. High deletion along with significant association of PHF2 methylation with FANCC methylation in both age groups and XPA methylation in group-A suggested PHF2 to be a candidate TSGs in BC. Reduced expression of PHF2 mRNA also supported this fact. Further analysis of PHF2 is required to assess its role in tumorigenesis.

\section{Conclusion}

Thus it may be concluded that impairment of multiple DNA repair pathways and PTCH1 associated self-renewal pathway are necessary for the development of both groups of BC. However, differential association of these genes with adverse patient outcome in both groups suggests their differences in molecular pathogenesis.

\section{Abbreviations}

ATCC: American Type Culture Collection; BC: Breast carcinoma; BCC: basal cell carcinoma; CGH: Comparative Genomic Hybridization; Chr.: Chromosome; HD: Homozygous deletion; HED: Hemizygous deletion; IHC: Immunohistochemisty; LOH: loss of heterozygosity; MSRA: Methylation Sensitive Restriction Analysis; NBCCS: nevoid basal cell carcinoma syndrome; NER: 
nucleotide excision repair; Q-PCR: Quantitative Real-time Polymerase Chain Reaction; SCC: squamous cell carcinoma; UICC: International Union against Cancer

\section{Competing interests}

The authors declare that they have no competing interests.

\section{Authors' contributions}

SS carried out the molecular genetic studies, participated in the sequence alignment and drafted the manuscript. RKS participated in the design of the study and performed the statistical analysis. NA provided the samples needed for this study. AR carried the histological studies. SR participated in its design and coordination and helped to draft the manuscript. CKP conceived of the study, and participated in its design and coordination and helped to draft the manuscript.

\section{Additional material}

\section{Additional file 1}

Pattern of alterations in early-onset ( 40 years) breast carcinoma. Click here for file

[http://www.biomedcentral.com/content/supplementary/14764598-7-84-S1.xls]

\section{Additional file 2}

Pattern of alterations in late-onset ( $>40$ years) breast carcinoma. Click here for file

[http://www.biomedcentral.com/content/supplementary/14764598-7-84-S2.xls]

\section{Additional file 3}

Frequency of methylation of chr.9q22.32-22.33 candidate genes in early- and late-onset breast carcinoma.

Click here for file

[http://www.biomedcentral.com/content/supplementary/14764598-7-84-S3.xls]

\section{Additional file 4}

Frequency of overall alterations (deletion/methylation) of candidate TSGs in breast carcinoma.

Click here for file

[http://www.biomedcentral.com/content/supplementary/14764598-7-84-S4.xls]

\section{Additional file 5}

Q-PCR data sheet for expression analysis of candidate TSGs.

Click here for file

[http://www.biomedcentral.com/content/supplementary/14764598-7-84-S5.xls]

\section{Additional file 6}

Association between overall alterations of the candidate TSGs at chr.9q22.32-22.33 and other DNA repair genes in early-and lateonset BC.

Click here for file

[http://www.biomedcentral.com/content/supplementary/14764598-7-84-S6.doc]

\section{Additional file 7}

Clinico-pathological correlation of deletion in different genes at chr.9q22.32-22.33 in Group-A and Group-B breast carcinomas. Click here for file

[http://www.biomedcentral.com/content/supplementary/14764598-7-84-S7.doc]

\section{Additional file 8}

Clinico-pathological correlation of methylation in different genes at chr.9q22.32-22.33 in Group-A and Group-B breast carcinomas. Click here for file

[http://www.biomedcentral.com/content/supplementary/14764598-7-84-S8.doc]

\section{Acknowledgements}

We are thankful to the Director, Chittaranjan National Cancer Institute, Kolkata-700026, India. I am also grateful to Dr. Sukta Das for her invaluable contribution in preparing the manuscript. Financial support was provided by CSIR - JRF/NET Fellowship grant [no. 9/30(03I)/2003- EMR-I] to Mr. S. Sinha.

\section{References}

I. Sen U, Sankaranarayanan R, Mandal S, Ramanakumar AV, Parkin DM, Siddiqi M: Cancer patterns in eastern India: the first report of the Kolkata cancer registry. Int J Cancer 2002, 100:86-91.

2. Chung M, Chang HR, Bland KI, Wanebo HJ: Younger women with breast carcinoma have a poorer prognosis than older women. Cancer 1996, 77:97-103.

3. Chunder N, Mandal S, Basu D, Roy A, Roychoudhury S, Panda CK: Deletion mapping of chromosome $I$ in early onset and late onset breast tumors-a comparative study in eastern India. Pathol Res Pract 2003, 199:313-32I.

4. Chunder N, Mandal S, Roy A, Roychoudhury S, Panda CK: Analysis of different deleted regions in chromosome $I I$ and their interrelations in early- and late-onset breast tumors: association with cyclin DI amplification and survival. Diagn Mol Pathol 2004, I 3: 172-182.

5. Foo CS, Su D, Chong CK, Chng HC, Tay KH, Low SC, Tan SM: Breast cancer in young Asian women: study on survival. ANZ J Surg 2005, 75:566-572.

6. Sinha S, Chunder N, Mukherjee N, Alam N, Roy A, Roychoudhury S, Kumar Panda C: Frequent deletion and methylation in SH3GL2 and CDKN2A loci are associated with early- and late-onset breast carcinoma. Ann Surg Oncol 2008, I 5: 1070- 1080.

7. Mitelman F, Mertens F, Johansson B: A breakpoint map of recurrent chromosomal rearrangements in human neoplasia. Nat Genet 1997:417-474.

8. Jain AN, Chin K, Borresen-Dale AL, Erikstein BK, Eynstein Lonning P, Kaaresen R, Gray JW: Quantitative analysis of chromosomal CGH in human breast tumors associates copy number abnormalities with p53 status and patient survival. Proc Natl Acad Sci USA 200I, 98:7952-7957.

9. Naylor TL, Greshock J, Wang Y, Colligon T, Yu QC, Clemmer V, Zaks TZ, Weber BL: High resolution genomic analysis of sporadic breast cancer using array-based comparative genomic hybridization. Breast Cancer Res 2005, 7:R I I86-II 98.

10. Korsching E, Packeisen J, Helms MW, Kersting C, Voss R, van Diest PJ, Brandt B, Wall E van der, Boecker W, Burger H: Deciphering a subgroup of breast carcinomas with putative progression of grade during carcinogenesis revealed by comparative genomic hybridisation (CGH) and immunohistochemistry. BrJ Cancer 2004, 90: I422-I428.

II. Lichun Y, Ching Tang CM, Wai Lau K, Lung ML: Frequent loss of heterozygosity on chromosome 9 in Chinese esophageal squamous cell carcinomas. Cancer Lett 2004, 203:7I-77.

12. Simoneau M, LaRue H, Aboulkassim TO, Meyer F, Moore L, Fradet Y: Chromosome 9 deletions and recurrence of superficial blad- 
der cancer: identification of four regions of prognostic interest. Oncogene 2000, 19:6317-6323.

13. Simoneau M, Aboulkassim TO, LaRue H, Rousseau F, Fradet Y: Four tumor suppressor loci on chromosome $9 q$ in bladder cancer: evidence for two novel candidate regions at $9 q 22.3$ and $9 q 31$. Oncogene 1999, 18:157-163.

14. Nowakowska B, Kutkowska-Kazmierczak A, Stankiewicz P, Bocian E, Obersztyn E, Ou Z, Cheung SW, Cai WW: A girl with deletion 9q22.I-q22.32 including the PTCH and ROR2 genes identified by genome-wide array-CGH. Am J Med Genet A 2007, I 43A: $1885-1889$.

15. D'Alessandro M, Coats SE, Morley SM, Mackintosh L, Tessari G, Turco A, Gerdes AM, Pichert G, Whittaker S, Brandrup F, et al: Multiple self-healing squamous epithelioma in different ethnic groups: more than a founder mutation disorder? J Invest Dermatol 2007, 127:2336-2344.

16. Wreesmann VB, Estilo C, Eisele DW, Singh B, Wang S): Downregulation of Fanconi anemia genes in sporadic head and neck squamous cell carcinoma. ORL J Otorhinolaryngol Relat Spec 2007, 69:218-225.

17. Haneline LS, Gobbett TA, Ramani R, Carreau M, Buchwald M, Yoder MC, Clapp DW: Loss of FancC function results in decreased hematopoietic stem cell repopulating ability. Blood 1999, 94:I-8.

18. Habi O, Delisle MC, Messier N, Carreau M: Lack of self-renewal capacity in Fancc-/- stem cells after ex vivo expansion. Stem Cells 2005, 23: II35-II4I.

19. Kitao H, Yamamoto K, Matsushita N, Ohzeki M, Ishiai M, Takata M: Functional interplay between BRCA2/FancDI and FancC in DNA repair. J Biol Chem 2006, 28 I:2 I | |2-2 I 320.

20. Neveling K, Kalb R, Florl AR, Herterich S, Friedl R, Hoehn H, Hader C, Hartmann FH, Nanda I, Steinlein C, et al.: Disruption of the FA/ BRCA pathway in bladder cancer. Cytogenet Genome Res 2007, I I8:166-176.

21. Heijden MS van der, Yeo CJ, Hruban RH, Kern SE: Fanconi anemia gene mutations in young-onset pancreatic cancer. Cancer Res 2003, 63:2585-2588

22. Couch FJ, Johnson MR, Rabe K, Boardman L, McWilliams R, de Andrade M, Petersen G: Germ line Fanconi anemia complementation group $\mathbf{C}$ mutations and pancreatic cancer. Cancer Res 2005, 65:383-386.

23. Shahi $\mathrm{MH}$, Lorente $\mathrm{A}$, Castresana JS: Hedgehog signalling in medulloblastoma, glioblastoma and neuroblastoma. Oncol Rep 2008, 19:68I-688.

24. Reifenberger J, Arnold N, Kiechle M, Reifenberger G, Hauschild A: Coincident PTCH and BRCAI germline mutations in a patient with nevoid basal cell carcinoma syndrome and familial breast cancer. J Invest Dermatol 200 I, I I 6:472-474.

25. Adolphe C, Hetherington R, Ellis T, Wainwright B: Patched I functions as a gatekeeper by promoting cell cycle progression. Cancer Res 2006, 66:208I-2088.

26. Wolf I, Bose S, Desmond JC, Lin BT, Williamson EA, Karlan BY, Koeffler HP: Unmasking of epigenetically silenced genes reveals DNA promoter methylation and reduced expression of PTCH in breast cancer. Breast Cancer Res Treat 2007, 105:139-155.

27. Asahina H, Kuraoka I, Shirakawa M, Morita EH, Miura N, Miyamoto I, Ohtsuka $E$, Okada $Y$, Tanaka $\mathrm{K}$ : The XPA protein is a zinc metalloprotein with an ability to recognize various kinds of DNA damage. Mutat Res 1994, 31 5:229-237.

28. Kuraoka I, Morita EH, Saijo M, Matsuda T, Morikawa K, Shirakawa M, Tanaka K: Identification of a damaged-DNA binding domain of the XPA protein. Mutat Res 1996, 362:87-95.

29. Patrick SM, Turchi J]: Xeroderma pigmentosum complementation group A protein (XPA) modulates RPA-DNA interactions via enhanced complex stability and inhibition of strand separation activity. J Biol Chem 2002, 277:16096-I6I0I.

30. Miller KL, Karagas MR, Kraft P, Hunter DJ, Catalano PJ, Byler SH, Nelson $\mathrm{HH}$ : XPA, haplotypes, and risk of basal and squamous cell carcinoma. Carcinogenesis 2006, 27:1670-1675.

31. Wang Y, Spitz MR, Lee J], Huang M, Lippman SM, Wu X: Nucleotide excision repair pathway genes and oral premalignant lesions. Clin Cancer Res 2007, 13:3753-3758.

32. Takebayashi $Y$, Nakayama K, Kanzaki A, Miyashita H, Ogura O, Mori S, Mutoh M, Miyazaki K, Fukumoto M, Pommier Y: Loss of heterozygosity of nucleotide excision repair factors in sporadic ovarian, colon and lung carcinomas: implication for their roles of carcinogenesis in human solid tumors. Cancer Lett 200I, I74:II5-125.

33. Hasenpusch-Theil K, Chadwick BP, Theil T, Heath SK, Wilkinson DG, Frischauf AM: PHF2, a novel PHD finger gene located on human chromosome 9q22. Mamm Genome 1999, 10:294-298.

34. Sobin LH, Wittekind C: TNM Classification of Malignant Tumors. 6th edition. New York: Wiley; 2002.

35. Dasgupta S, Mukherjee N, Roy S, Roy A, Sengupta A, Roychowdhury S, Panda CK: Mapping of the candidate tumor suppressor genes' loci on human chromosome 3 in head and neck squamous cell carcinoma of an Indian patient population. Oral Oncol 2002, 38:6-15.

36. Tripathi Bhar A, Banerjee S, Chunder N, Roy A, Sengupta A, Roy B, Roychowdhury S, Panda CK: Differential alterations of the genes in the CDKN2A-CCNDI-CDK4-RB I pathway are associated with the development of head and neck squamous cell carcinoma in Indian patients. J Cancer Res Clin Oncol 2003, 1 29:642-650.

37. Ichimura K, Bolin MB, Goike HM, Schmidt EE, Moshref A, Collins VP. Deregulation of the $\mathrm{p}$ I4ARF/MDM2/p53 pathway is a prerequisite for human astrocytic gliomas with $\mathrm{GI}$-S transition control gene abnormalities. Cancer Res 2000, 60:417-424.

38. Loginov VI, Maliukova AV, Seregin lu A, Khodyrev DS, Kazubskaia TP, Ermilova VD, Gar'kavtseva RF, Kiselev LL, Zabarovskii ER, Braga EA: [Methylation of the promoter region of the RASSFIA gene, a candidate tumor suppressor, in primary epithelial tumors]. Mol Biol (Mosk) 2004, 38:654-667.

39. Ivanova T, Petrenko A, Gritsko T, Vinokourova S, Eshilev E, Kobzeva $\mathrm{V}$, Kisseljov F, Kisseljova N: Methylation and silencing of the retinoic acid receptor-beta 2 gene in cervical cancer. $B M C$ Cancer 2002, 2:4.

40. Livak KJ, Schmittgen TD: Analysis of relative gene expression data using real-time quantitative PCR and the 2(-Delta Delta C(T)) Method. Methods 200I, 25:402-408.

4I. Milde-Langosch K, Bamberger AM, Rieck G, Kelp B, Loning T: Overexpression of the p/6 cell cycle inhibitor in breast cancer is associated with a more malignant phenotype. Breast Cancer Res Treat 2001, 67:61-70.

42. Chunder N, Mandal S, Roy A, Roychoudhury S, Panda CK: Differential association of BRCAI and BRCA2 genes with some breast cancer-associated genes in early and late onset breast tumors. Ann Surg Oncol 2004, I I:1045-1055.

43. Mizuno T, Tokuoka S, Kishikawa M, Nakashima E, Mabuchi K, Iwamoto KS: Molecular basis of basal cell carcinogenesis in the atomic-bomb survivor population: $\mathrm{p} 53$ and PTCH gene alterations. Carcinogenesis 2006, 27:2286-2294.

Publish with Bio Med Central and every scientist can read your work free of charge

"BioMed Central will be the most significant development for disseminating the results of biomedical research in our lifetime."

Sir Paul Nurse, Cancer Research UK

Your research papers will be:

- available free of charge to the entire biomedical community

- peer reviewed and published immediately upon acceptance

- cited in PubMed and archived on PubMed Central

- yours - you keep the copyright 